\title{
The Efficiency of a Bus Rapid Transit Utilizing a Passenger Information System
}

\author{
Mudjiastuti Handajani \\ Faculty of Engineering \\ Semarang University \\ Semarang, Indonesia \\ mudjiastuti@usm.ac.id
}

\author{
Andi Kurniawan Nugroho \\ Faculty of Engineering \\ Semarang University \\ Semarang, Indonesia \\ andikn76@gmail.com
}

\author{
Harmini \\ Faculty of Engineering \\ Semarang University \\ Semarang, Indonesia \\ harmini@usm.ac.id
}

\begin{abstract}
Incredible city transportation utilizing a safe, comfortable, stable, and efficient smart transportation system with modern arrangements has become a necessity. Currently, the transit busses still run on the open road in mixed traffic, which means the arrival times cannot be anticipated correctly. Furthermore, using the Department of Transportation's Passenger Information System (PIS) and GPS effectively and efficiently provides immediate information about the position of each bus. The PIS monitoring system transmits the accompanying information using the GSM method and continuously provides arrival times to passengers through their smartphones. The PIS screen can be monitored at each bus stop, as well as by the Department of Transportation, to confirm the arrival times for each bus. This is useful for bus users and operators and encourages private vehicle users to switch to mass transit.
\end{abstract}

Keywords: monitoring, passenger, information, system, Semarang

\section{INTRODUCTION}

Semarang is a metropolitan city participating in the smart city program by implementing a transportation system that is reliable, fun, inexpensive, convenient, environmentally friendly, effective, and efficient. Supriyanto et. al [1], explained that the best approach to urban transport in an area with a high population is mass transportation. According Handajani [2] and Sukarto [3], mass transportation services in the Semarang metropolitan area previously accommodated only $7 \%$ of the population. In Singapore, a more developed country, mass transportation services reached $85 \%$ of the population, Handajani [4]. According to Fanani et. al [5], building a smart transportation system via a bus arrival prediction software is a noteworthy challenge because of the impact passengers have on the waiting times.

The goal of this research therefore is to encourage potential passengers to use the BRT by providing bus arrival information that passengers can predict. However, these efforts face obstacles given the fact that the Trans Semarang Bus runs in mixed traffic and the arrival times are often inaccurate. Therefore, it is important to introduce a system of monitoring and PIS in order to provide bus arrival information in real time. Passengers can design departure and arrival times effectively and efficiently following their scheduled destinations. Another goal of this research is to encourage individuals to rely on the BRT instead of on private vehicles. Increasing the accessibility and convenience of public transportation can also change a city's travel network by reducing its fuel consumption per capita, Andre et. al [6] and Handajani [7].

In Tokyo, systems displaying the real time location of each city bus are already used. The system uses ring tones or vibrations to indicate that a bus has almost reached a specific passenger's destination, and to prevent them from missing their stop on the route they've laid out. However, the transit speed cannot be shown, Yutaka [8]. This BRT system has been equipped with a tracking device; therefore each passenger can be seen in each shelter via a monitor and be accessed via smartphone. It may soon be possible to equip every bus to track GPS signals and chip cards as well.

\section{A. The Framework Passenger Information System}

A PIS and digital monitoring are intended to track the location of each bus. They use a web server to determine the busses positions in real time, along with web applications for each passenger to use. Framework for the PIS can be found in Fig. 1.

The design framework for the PIS uses a database and server connected to the satellite. GPS is installed in each bus and the tracking screens are installed at each bus stop. The whole PIS system is monitored from the Semarang Transportation Office.

The framework of the PIS has three main modules, specifically:

1) Busses installed with a GPS tracking system

2) A Clent-Side application at each bus stop

3) A central control center system including a user command receiver that monitors the position of each BRT bus in real time.

The server is intended to mediate between the module itself and the passengers/users of the module transport application. The database contains arrivals and departures, bus routes, passenger information, and the real time location of each bus. The GPS transmits information about the latitudes and longitudes, which is then stored in the PC's framework. Meanwhile, current and prospective passengers can use the application to indicate their entry points into the BRT system and destinations. The application automatically displays the number of passengers at each stop and calculates the time it will take to reach those passengers. Furthermore, the framework will continuously refresh the 
latitudinal and longitudinal position of each bus. GUI frameworks and monitoring displays each bus's location and predict the arrival time for the passengers. This procedure is repeated for every search performed by the current and prospective passengers.

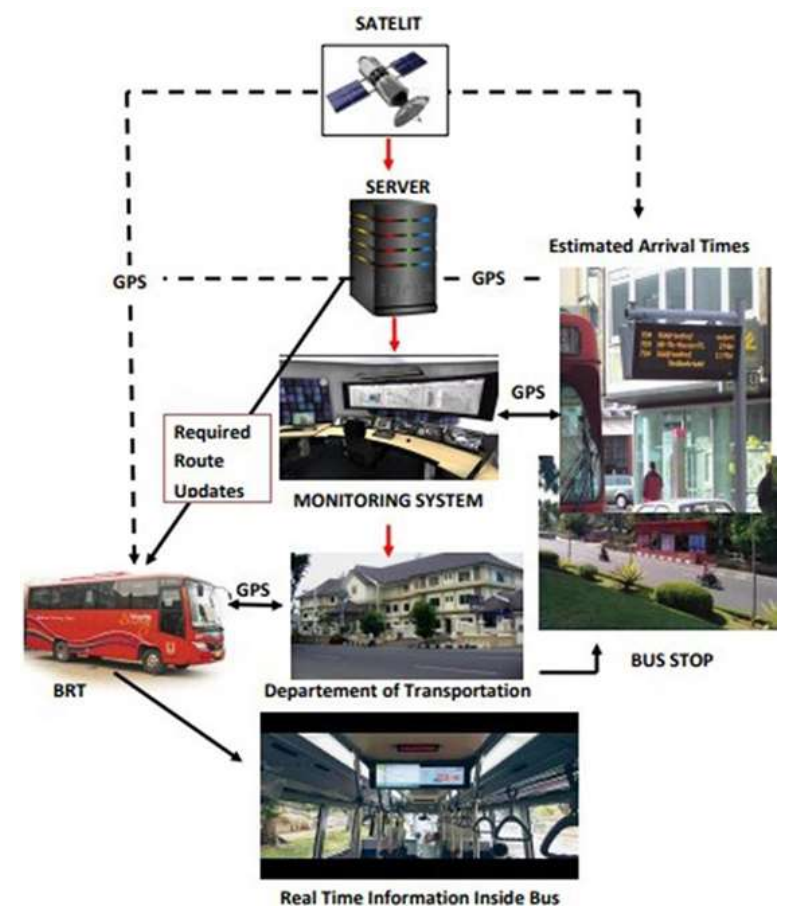

Fig. 1. Framework of the monitoring and PIS.

\section{RESEARCH METHODOLOGY}

Information is accumulated by reviewing and obtaining the necessary primary data within the BRT systemspecifically the speeds, routes, arrival and departure times, the differences in arrival times, the distances between stops, the state stops, and the interviews and division questioner-and secondary data. Secondary data includes the number of vehicles in operation, the schedules and coordinates, the service, the number of stops, the condition of each stop, and the type of bus in use. The flowchart of the study is shown in Fig. 2.

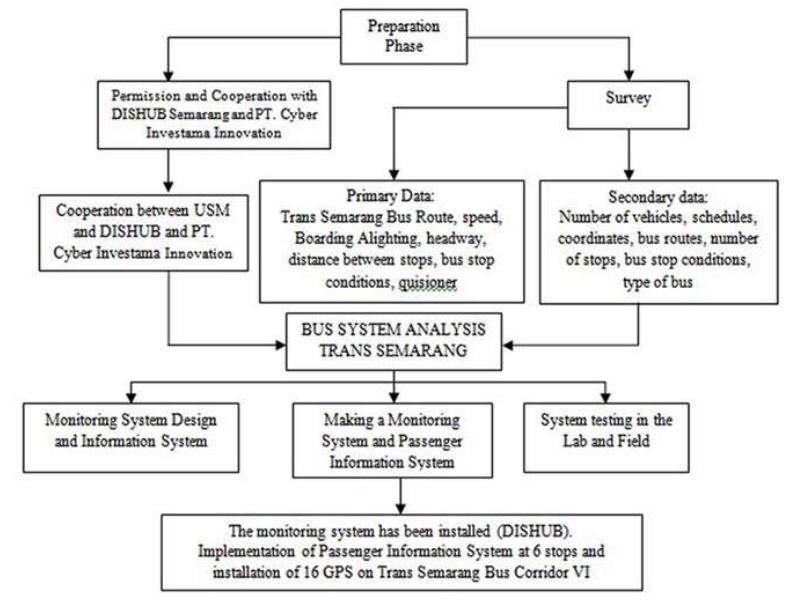

Fig. 2. Flowchart of research.
This research promotes innovative transportation for urban areas in Semarang, Indonesia. It supports the creation of real time transportation monitoring systems like the PIS, which is reliable, sustainable, modern, environmentally friendly, easy, simple, and fun. It also encourages communities to change their travel behavior and switch from private vehicle use to using mass transportation instead.

\section{A. Passenger waiting time}

Passenger waiting time is affected by the level of headway (arrival time difference of the bus following the same path). The longer the headway, the more extended the waiting time for passengers and vice versa. A survey was conducted using primary data from headway Bus Trans in Semarang between $5-7$ minutes, with the difference in arrival time estimated for the next bus at $3-7$ minutes.

\section{RESUlTS AND DISCUSSION}

\section{A. Semarang Research BRT Corridor VI}

BRT Route corridor consists of VI corridor directions from Diponegoro University to Semarang State University. It is an educational path that requires proper adjustments for the public and surrounding environment. Bus Trans Semarang route map is shown in Fig. 3.

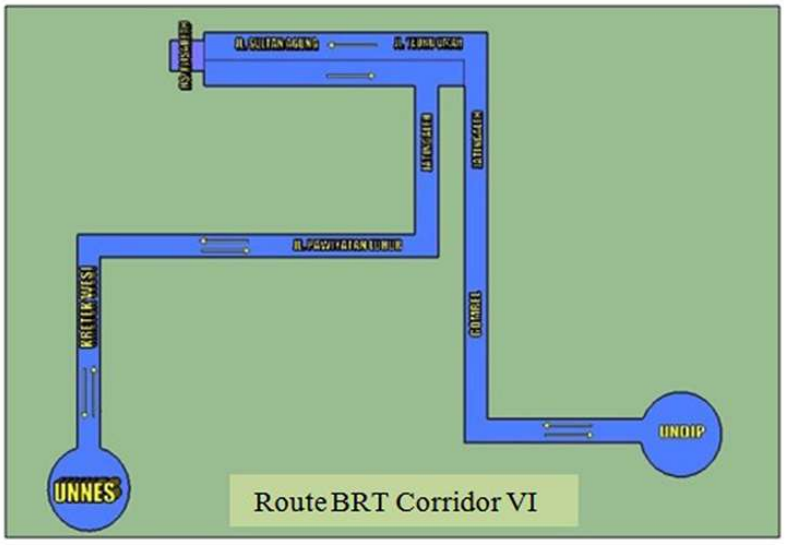

Fig. 3. Map of the BRT route corridor VI.

Normal Speed Corridor VI BRT obtained comparison with a mileage commute route of $42.4 \mathrm{~km}$. A total of 20.1 $\mathrm{km}$ is covered from the Diponegoro University to Semarang State University and in the reverse direction it is $22.3 \mathrm{~km}$. Chart comparison of normal travel time and speed BRT is found in Fig. 4.
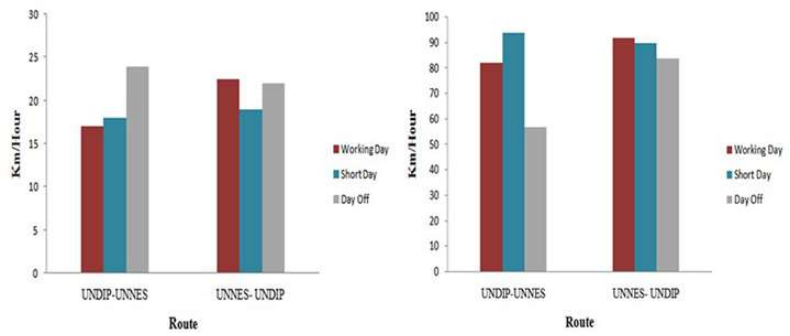

Fig. 4. Comparison of travel time and average speed corridor VI BRT. 


\section{B. Distribution of Demand}

The location of educational institutions, workplace, malls and residential buildings, are in high demand which affects the functions of bus stops, and tends to cause congestion on the roads, especially around the transSemarang and other transportation modes. The various bus stops with the highest demand areas are located on Corridor VI are shown in Fig. 5.

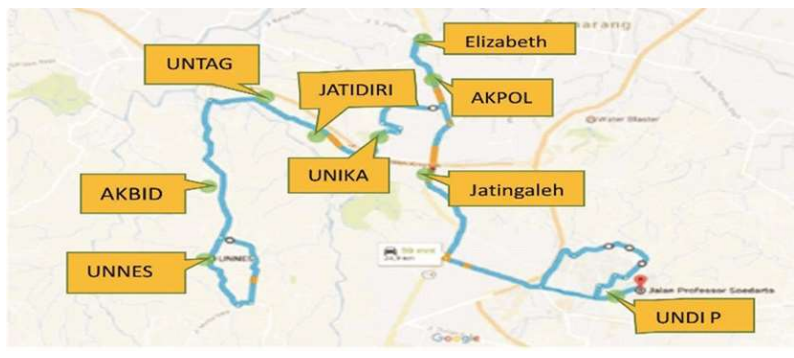

Fig. 5. Location trans-Semarang bus stop with a high demand on the corridor VI.

PIS have been installed at Elizabeth and Kesatrian bus stops due to its high level of demand proportion, with the monitoring system installed at the Department of Transportation's Office of Semarang. Furthermore it is installed in 3 stops in the Diponegoro University, Catholic University, and Semarang State University, with the 7 transSemarang Bus currently in execution procedure. Fig. 6 and Fig. 7 shows these bus stops.

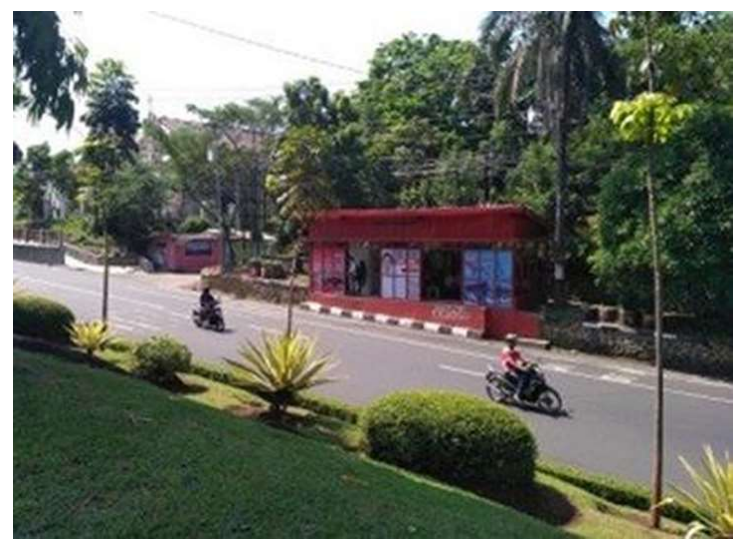

Fig. 6. Bus stop condition Elizabeth.

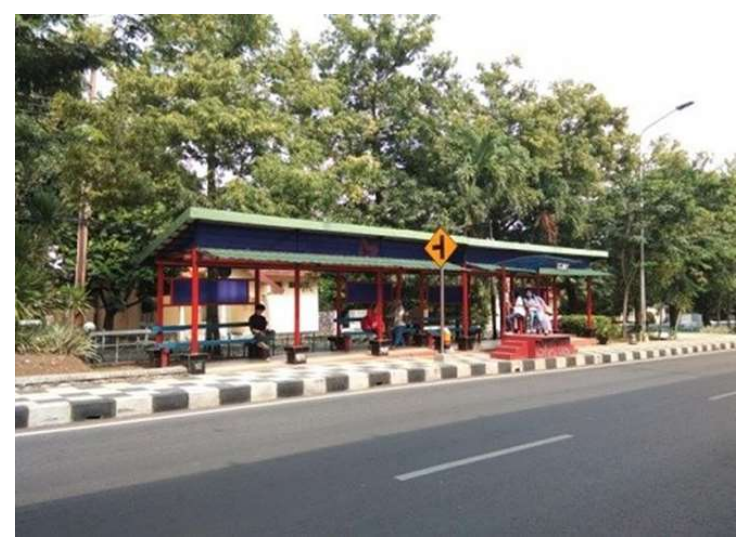

Fig. 7. Bus stop condition Kesatrian.

\section{The Main Module Monitoring Device and a Passenger Information System}

a) Bus unit: There is a GPS tracker module on the bus, GSM modem and microcontroller which serves to transmit information in the form of bus position coordinates. Its latitude and longitude lines are stored in a PC's framework, which consists of real-time data, such as bus routes, departure and arrival time, number of passengers and realtime position of the bus. Fig. 8 is a GPS photo installed in trans-Semarang Bus.

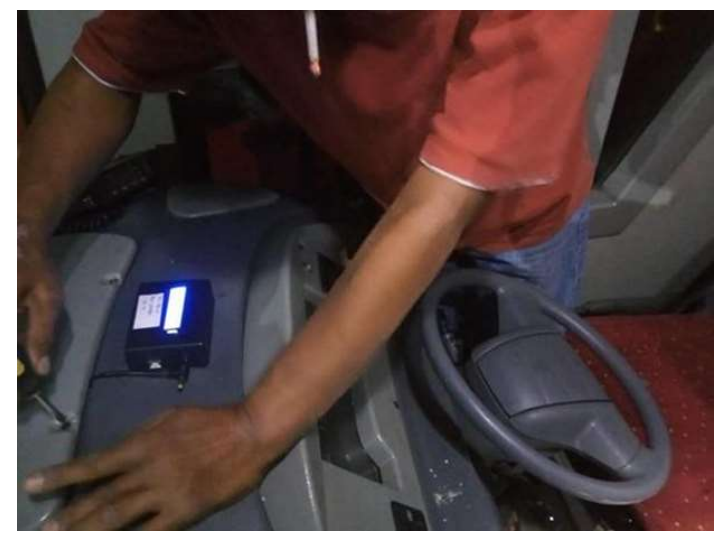

Fig. 8. GPS installed in the BRT.

These devices obtain the GPS data and periodically transmit and check the information in the server. To obtain a signal in an ideal place, a GPS reception antenna jack is allocated to the right, and another to the SIM card which receives signals from a GSM tower and transmits to the application user/passenger. Links are associated with the positive and negative power supply system bus. To obtain the signal from the satellite, the GPS device is started, which is able to obtain the current location of the bus through latitude and longitude lines at each time interval.

b) Client-side application: In a client-side application, passengers are able to get to their destinations with the number of buses found through interactive web-based electronic applications. The PIS application users produced buses operating within the scanned area of travel time from the current position to the prospective bus passengers' location. This is achieved because there are a receiver unit and a GUI displayed in real-time on the client-side user application. Besides, the system also refreshes or updates coordinate of the bus arrival time to the passengers. PIS is mounted on stop Elizabeth is shown in Fig. 9.
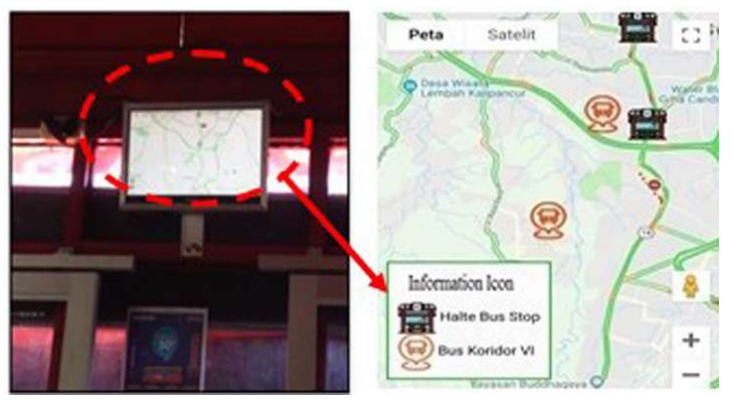

Fig. 9. Client-side stop application installed in Elizabeth. 
c) Central control unit: When the recipient of the information regarding a bus unit stored in a database sends a request, the instrument records the request for the server to read and provide a list of accessible buses in accordance with the purpose of supply. PIS users have the ability to see the bus range or other information contained in the application. After selecting the bus number, the application shows its position on the user's screen in the form of arrival and departure time. The cycle is repeated for each search performed by the user application to obtain information on the host bus which suits the passengers' purpose. The central control unit mounted on Transportation Semarang Office is shown in Fig. 10.

A PIS is a modern attendance monitoring system used to provide reliable transport foundation, in real-time, which helps to plan a city's transportation system, Advait [9]. Furthermore, it is a smart transportation system for urban areas in Indonesia, especially in the city of Semarang.

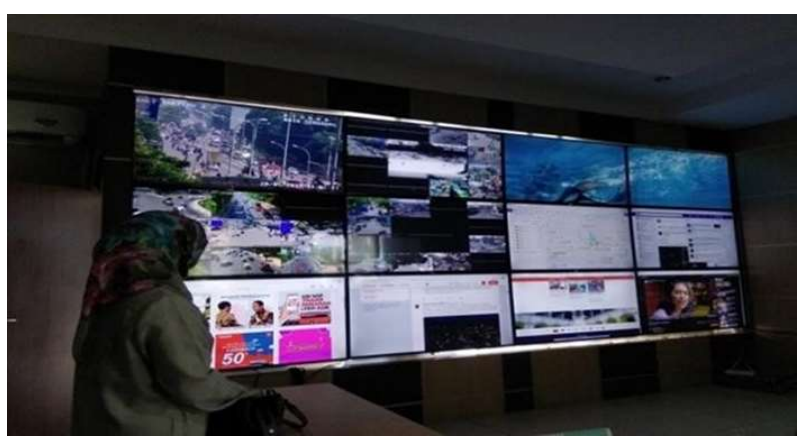

Fig. 10. Central control unit mounted on DISHUB Semarang.

\section{Overview of the Economic Aspects}

The use transportation Bus Trans Semarang modes, tends to reduce fuel consumption owing to its ability to reduce travel costs. When compared to private vehicles, the Trans Semarang Bus from Diponegoro University to Semarang State University has an average motorcycle and bus fuel consumption rate of $40 \mathrm{~km} / \mathrm{liter}$, and $3.2 \mathrm{~km} / \mathrm{liter}$ respectively. Furthermore, the distance from Diponegoro to Semarang State University is $20.1 \mathrm{~km}$ (BRT performance Analysis, 2017).

Correlation mileages with fuel consumption of motorcycles produce 0.5 liters per motorcycle, which means that when two passengers board it, each consumes 0.25 liters. Furthermore, the motorcycles produce 6.28 liters per bus consumption, due to its ability to carry 40 passengers, at 0.16 liters. Pertamina's latest fuel price chart is presented in Fig. 11.

\section{E. Assessing the Environmental Aspects}

Supriyanto et. al [1], Suggested that city transportation to urban areas consists of high population density which is the key to controlling fuel utilization. Emission Factor Calculation Result by Type Vehicle in Fig. 12.

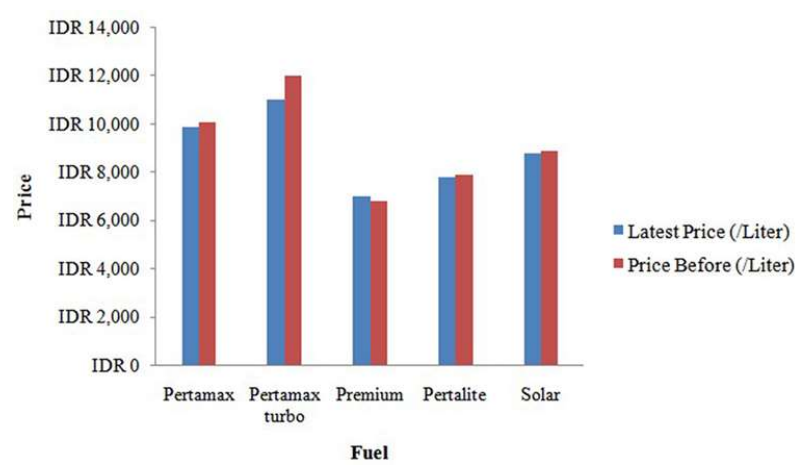

Fig. 11. Fuel prices latest Pertamina.

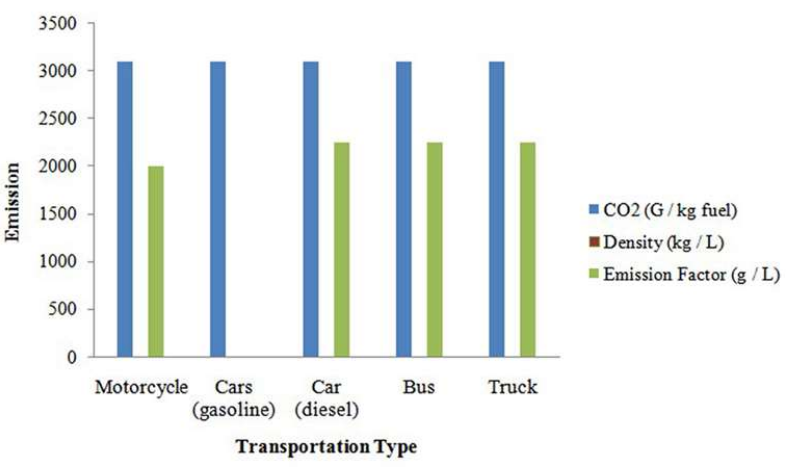

Fig. 12. Emission Factor Calculation Result by Type Vehicle.

The emission factor is derived by multiplying $\mathrm{CO}_{2}$ density. The proportion of Bus Transit users in Semarang is 40 people for motorcycle, with a minimum of 2 people. The consequences of the release of each factor are 1: $72 \mathrm{~g} / \mathrm{l}$, which means that every passenger motorcycle provides 72 times the smoke generated by the mass transit (Trans Semarang Bus).

\section{F. Benefits of Using Monitoring Analysis and PIS}

Analysis monitoring and PIS tools implemented in the first year, is conducted by spreading online questionnaire which was responded by 130 people. Passengers tend to use either direct bus, or private vehicles.

According to the survey, $96.9 \%$ of respondents stated that the use of monitoring devices and PIS was very useful for public transport passengers while $89.2 \%$ opined that it tends to attract private vehicle users to switch to public transportation. Approximately $100 \%$ of the respondents expected the implementation of the Monitoring and PIS system in corridor Buses. $85.3 \%$ of the existing conditions of society are rarely used due to lack of service facilities Bus modes of public transportation are reliable, safe, comfortable, efficient and modern. Monitoring device and PIS are installed on GPS Bus stops and is beneficial for passengers, bus operators, and the Department of Transportation as organizing transport. People are happy to use the bus owing to the certainty of time, with the questionnaire result shown in Fig. 13. 

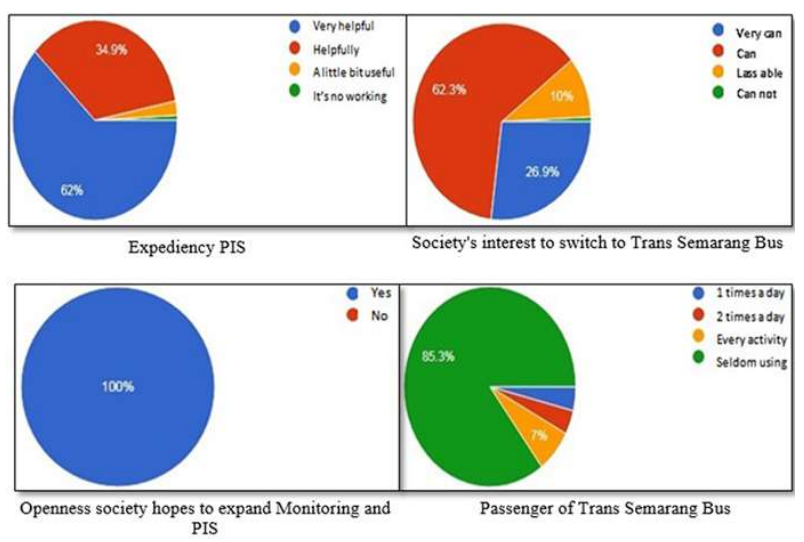

Fig. 13. Result of the questionnarie responses PIS first year.

\section{CONCLUSIONS}

The implementation of monitoring devices, GPS, and Passenger Information System at bus stops is useful to streamline passenger transit time, bus locations, and used by the Department of Transportation Semarang for proper transportation management. This tends to make the society happy as transportation became more effective, efficient, fuel-efficient and environmentally friendly. Therefore, passengers travel using mass transportation integrated with Monitoring devices and PIS thereby, making traveling more efficient. It also tends to make private transportation users switch to use public transport, to create easy and free flow of traffic.

\section{ACKNOWLEDGMENT}

The author is grateful to the Research Technology and Higher Education of the Republic of Indonesia, Semarang City Department of Transportation and the Semarang University, for the opportunity and support in carrying out this Integrated Research GRANTS Leading Higher Education, Transportation, University of Semarang.

\section{REFERENCES}

[1] Supriyanto D, and Wijayanti A, et al. City Bus Service Performance in Surabaya, Journal of Transport, FSTPT. 2010; Vol.10.

[2] Handajani M. Efficient Solutions Fuel (BBM) Towards Sustainable Transportation, 2016.

[3] Sukarto H. Urban Transport, and Environment, Civil Engineering Journal. 2006; Vol.3: No. 2.

[4] Handajani M. Fuel Consumption Semarang and Surakarta in terms of the transport system and Typology City, Journal of Transportation, Transport Study Forum for Higher Education. 2013; Vol.13: No. 3: page 223-232.

[5] Fanani L, Basuki A, Liang D, et al. Bus Arrival Prediction - to Ensure Users not to Miss the Bus, International Journal of Electrical and Computer Engineering (IJECE). 2015; Vol.5, No. 2.

[6] Andre D, Susan K., and Shannon P, et al, Risk of Energy Constrained Activity-Transport System (RECATS), Journal of the Eastern Asia Society for Transportation Studies. 2007; vol.7: 11541168.

[7] Handajani M, Non-Linear Model City Transportation System and Control of Fuel Consumption, IJCER. 2012; Vol. 2: Issue 2: Page. 228-235.

[8] Yutaka I, Passenger Location Information System, Portable Information Terminal and Server, 2010.

[9] Advait V, and Kevin T, The Role of VGI in Modeling Future Energy Demand, USA, 2009. 